\title{
PESQUISAS COM NORBERT ELIAS EM HISTÓRIA DA EDUCAÇÃO
}

\author{
RESEARCHES WITH NORBERT ELIAS \\ IN THE HISTORY OF EDUCATION
}

\section{INVESTIGACIONES CON NORBERT ELIAS EN HISTORIA DE LA EDUCACIÓN}

TONY HONORATO 'Universidade Estadual de Londrina (UEL), Londrina/PR - Brasil.

Resumo O texto objetiva apresentar um quadro de pesquisas em História da Educação disseminadas na comunidade acadêmica e produzidas a partir das teorias de Norbert Elias. Os conceitos privilegiados são: figuração, poder, Estado e gênio. Tais constructos nos possibilitaram interpretações sobre a história das instituições escolares como monopólios do Estado, das escolas de formação de professores como figurações de relações de poder e das trajetórias de educadores intelectuais como um entrecruzamento do pedagógico, cultural, político, artístico e social. Os temas abordados recaíram a respeito da sociedade brasileira do século XIX e início do XX.

Palavras-chave: Norbert Elias; Teoria; História da educaÇão; Instituição escolar; FORMAÇÃO DE PROFESSOR.

Abstract The text aims to present a chart of research in the History of Education disseminated in the academic community and produced from the theories of Norbert Elias. The privileged concepts are: figuration, power, state and genius. Such constructs enabled us to interpret the history of school institutions as state monopolies, teacher training schools as power relations figurations and the trajectories of intellectual educators as an interlacement of pedagogical, cultural, political, artistic and social. The topics covered are about the Brazilian society in the nineteenth and early twentieth centuries.

Key-words: Norbert Elias; Theory; History of Education; School Institution; Teacher TRAINING. 
RESUMEN El texto tiene como objetivo presentar un cuadro de investigaciones en Historia de la Educación diseminadas en la comunidad académica y producidas a partir de las teorías de Norbert Elias. Los conceptos privilegiados son: figuración, poder, estado y genio. Tales construcciones nos posibilitaron interpretaciones sobre la historia de las instituciones escolares como monopolios del Estado, de las escuelas de formación de profesores como figuraciones de relaciones de poder y de las trayectorias de educadores intelectuales como un entrecruzamiento del pedagógico, cultural, político, artístico y social. Los temas abordados recayeron sobre la sociedad brasileña del siglo XIX y principios del XX.

Palabras clave: Norbert Elias; Teoría; Historia de la educación; Institución escolar; FORMACIÓN DE PROFESOR.

\section{INTRODUÇÃo}

Intenta-se, neste artigo, ${ }^{1}$ mobilizar algumas de nossas pesquisas em história da educação que operam com categorias analíticas sistematizadas a partir do constructo teórico-metodológico proposto por Norbert Elias. Para Chartier (1990) e Burke (2005), a obra de Norbert Elias é no contexto da história cultural uma referência e alternativa à história economicista e positivista. No nosso entendimento, ela cumpre também uma contribuição importante aos estudos histórico-culturais da educação crescentes nas duas últimas décadas.

Norbert Elias (nascido em Breslau, em 1897, e morto em Amsterdam em 1990), considerado um expoente do pensamento social do século $\mathrm{XX},{ }^{2}$ em sua trajetória intelectual, entre outros temas, chama a atenção para um problema conceitual localizado no pensamento sociológico de sua época: trata-se do entendimento de que indivíduo e sociedade são estruturas isoladas e controladas em termos deterministas. Ao contrário, Elias propõe-se a pensar a constituição do indivíduo e da sociedade em termos relacionais e processuais ao longo do tempo. A solução aparenta bastante simples, mas provoca questões que exigem respostas não rudimentares. Por exemplo: como são estabelecidas as relações entre indivíduos e sociedade? Em que consistem as mudanças sociais e as da personalidade do indivíduo? Por que os padrões de comportamentos são, cada vez mais, controlados e refinados no modo de vida em sociedade? Como se dão as mudanças no longo prazo? São questões que Norbert Elias buscou responder por meio de problematização no sentido de dar inteligibilidade à singularidade e à sociabilidade humana a partir de conceitos, como: civilização, figuração, processos sociais, interdependência, individualização, habitus, poder, (auto)controle das emoções.

$\mathrm{Na}$ obra de Norbert Elias, esses conceitos tornam-se evidentes nos fundamentos da Teoria dos Processos Civilizadores, da Sociologia Figuracional e da Teoria Simbólica (ELIAS, 1980; 1993; 1994a; 1994b; 1994c; 1994d; 1995; 1997; 1998; 2000; 2001a; 2001b;

\footnotetext{
1 Este artigo representa a tradução, os avanços e o aprofundamento das questões apresentadas no texto em espanhol intitulado La teoria de Norbert Elias y una agenda de investigación en historia de la educación (HONORATO, 2016).

2 A respeito da vida e obra de Norbert Elias, entre outros, conferir: Elias (2001a); Heinich (2011); Gebara (2005); Zabludovsky (2007); site <www.norberteliasfoundation.nl/>.
} 
2006). Os conceitos são também metodológicos, ao passo que são articulados para a pesquisa e a leitura de uma dada realidade relacional e processual empiricamente verificável. Nesse sentido, segundo Elias, as pesquisas empíricas, na dimensão micro e macro e de curta e de longa duração histórica, são fundamentais para a produção e a revisão do conhecimento na área da Sociologia e da História, e, em nosso caso, da História da Educação.

Assim, a matriz interpretativa proposta inicialmente por Norbert Elias é inspiração teórica e metodológica que representa um auxílio a formular novos ângulos de observação e questionamentos para a história da educação, particularmente das instituições escolares e das pessoas formando figurações específicas. Então, a seguir passamos a apresentar um quadro de pesquisas em educação disseminadas na comunidade acadêmica e a exibir conceitos eliasianos que têm contribuído para produzirmos uma agenda de pesquisa com os seguintes temas no campo da história da educação: instituição escolar como monopólio do Estado, escolas de formação de professores, relações de poder e intelectuais da educação.

\section{SIPCS: UM QUADRO DE PESQUISAS EM EDUCAÇÃo}

Nas duas últimas décadas, tem aumento significativamente o interesse de pesquisadores do campo da Educação pelas teorias de Norbert Elias (Cf. Quadro 1). Na realidade brasileira, isso se deve por inúmeras razões, entre elas pela busca de diferentes ângulos analíticos das relações humanas nas figurações educativas, pelo maior acesso aos livros de Elias traduzidos para o idioma português e o espanhol, pela ampliação do mercado editorial, pela expansão dos programas de pós-graduação que ofertam cursos sobre as teorias eliasianas, pela organização dos grupos de pesquisa cadastrados no Conselho Nacional de Desenvolvimento Científico e Tecnológico (CNPq/Diretório de Grupos), ${ }^{3}$ pelos avanços tecnológicos da internet, permitindo maior interconectividade entre estudiosos em escala local, regional, nacional e internacional.

No texto Norbert Elias no Brasil, Gebara (2014) argumenta que a difusão do pensamento de Norbert Elias também se deu pelo processo de circulação da cultura cada vez mais multipolarizado e menos sujeito à autoridade de leitores privilegiados. Conforme o autor, os Simpósios Internacionais Processos Civilizadores (SIPCs) têm sido um lugar amplo para inserção, disseminação e atualização de pesquisadores interessados.

Nesse sentido, objetivando sistematizar um quadro de pesquisas sobre Educação produzidas com o aporte das teorias de Norbert Elias, empreendemos um levantamento bibliográfico quantitativo das produções disseminadas nos Anais dos Simpósios Internacionais Processos Civilizadores (1996-2012).

O levantamento se deu sobre 14 anais dos SIPCs, localizados na base de dados da homepage do Grupo de Pesquisa Processos Civilizadores. ${ }^{4}$ Os anais foram publicados entre

\footnotetext{
3 À guisa de referência: Grupo de Pesquisa Processos Civilizadores (CNPq/UEL - Universidade Estadual de Londrina); Grupo de Pesquisa Educação e Processo Civilizador (CNPq/UFGD - Universidade Federal da Grande Dourados).

4 Cf. http://www.uel.br/grupo-estudo/processoscivilizadores/portugues/anaisdosipc.htm
} 
1996 e 2012, sendo um publicado em Buenos Aires/Argentina, outro em Bogotá/Colômbia e os demais no Brasil..$^{5}$ Os textos estão em suporte impressos digitalizados (livros Anais $-1^{\circ}$. ao $6^{\circ}$. evento) e eletrônicos (Cd-rom Anais $-7^{\circ}$. ao $14^{\circ}$. evento). Como resultado, o corpus documental foi constituído por uma série de 688 textos, como verifica-se a seguir:

Quadro 1: Temáticas publicadas nos Anais dos SIPCs (1996-2012)

\begin{tabular}{|c|c|c|}
\hline TEMÁTICAS & N. Artigos & $\%$ \\
\hline Educação & 159 & 23,10 \\
\hline Esporte & 90 & 13,10 \\
\hline Teorias, conceitos e métodos & 88 & 12,80 \\
\hline Norbert Elias e interlocutores & 54 & 7,80 \\
\hline Indígenas, negros e questões étnicas & 45 & 6,50 \\
\hline Sociedades, Estados, cidades & 37 & 5,40 \\
\hline Identidades, grupos sociais & 32 & 4,70 \\
\hline Violência, poder & 31 & 4,50 \\
\hline Corpo, arte, natureza & 31 & 4,50 \\
\hline Gerações, infância, jovens & 31 & 4,50 \\
\hline Trabalho, empresas & 27 & 3,90 \\
\hline Lazer & 25 & 3,60 \\
\hline Literatura & 24 & 3,50 \\
\hline Emoções e outros & 14 & 2,10 \\
\hline Total: & 688 & $100 \%$ \\
\hline
\end{tabular}

Fonte: Anais dos SIPCs. Quadro elaborado pelo autor.

Para a seleção dos textos, assumiu-se como indicadores a leitura dos títulos, resumos, palavras-chave, introdução e considerações finais. A produção sobre a temática Educação é a maior, totalizando 159 textos $(23,10 \%)$.

Nota-se a existência de um volume significativo de textos na temática esporte, lazer e corpo, isso muito em razão da organização do SIPC ter sido gestada, em 1996, por professores $^{6}$ e estudantes vinculados à Faculdade de Educação Física da Universidade Estadual

5 Mais dois anais foram publicados, o da edição do evento realizado, em 2014, na Universidade Nacional Autônoma do México (UNAM) e o da edição de 2016, sediada pela Universidade Federal do Espírito Santo, Brasil (UFES). Por ora, tais anais deixaram de ser consultados por não estarem ainda disponíveis na base on-line do Grupo de Pesquisa Processos Civilizadores, acervo consultado.

6 Entre eles: Prof ${ }^{\mathrm{a}}$. Dra ${ }^{\mathrm{a}}$. Maria Beatriz Rocha Ferreira e Prof. Dr. Ademir Gebara. 
de Campinas (FEF/UNICAMP), onde ocorreram a primeira e também a segunda, a quarta e a décima edição do evento. ${ }^{7}$ Ainda, destaca-se que Norbert Elias orientou um dos mais reconhecidos sociólogos do esporte e do lazer, Eric Dunning, que fora professor do Departamento de Sociologia da Universidade de Leicester. Dunning e Elias assinam em autoria a obra The quest for excitement: sport and leisure in the civilizing process, bastante referenciada pelos estudos brasileiros, sobretudo, na versão da tradução portuguesa intitulada $A$ busca da excitação e na tradução espanhola Deporte y ócio en el proceso de la civilización.

Os textos sobre educação são identificados em maior número a partir da terceira edição do SIPC, organizada no contexto do Programa de Pós-Graduação em Educação (PPGE) da Universidade Metodista de Piracicaba (UNIMEP), e passaram a ocupar cada vez mais lugar nas edições dos eventos seguintes e representam atualmente a temática de maior quantitativo.

Vejamos no Quadro 2 uma lista de assuntos de educação abordados pela produção consultada:

Quadro 2: Assuntos de educação presentes nos textos dos Anais dos SIPCs (1996-2012)

\begin{tabular}{|c|c|c|c|c|c|c|c|c|c|c|c|c|c|c|c|}
\hline $\begin{array}{l}\text { Assuntos artigos/Edição } \\
\text { SIPC }\end{array}$ & $I$ & $I I$ & III & $I V$ & V & $V I$ & $V I I$ & VIII & $I X$ & $X$ & $X I$ & $X I I$ & $X I I I$ & $X I V$ & Total \\
\hline $\begin{array}{l}\text { Norte-americanos, Protes- } \\
\text { tantes e instituições }\end{array}$ & & & 2 & & & 1 & 7 & 1 & 3 & 5 & & 2 & & 1 & 22 \\
\hline Universidade no Brasil & & & 1 & & & 1 & & & & & & & & 1 & 3 \\
\hline $\begin{array}{l}\text { Idade Média, Escolástica, } \\
\text { Ed. Cavaleiresca }\end{array}$ & & & & & & 3 & & & & & & & & & 3 \\
\hline $\begin{array}{l}\text { Colônia, Jesuítas, religiosi- } \\
\text { dade, Portugal }\end{array}$ & & & & & & 1 & 4 & & 1 & & & & & 2 & 8 \\
\hline $\begin{array}{l}\text { Extensão universitária, } \\
\text { educação física }\end{array}$ & & & & & & 2 & 1 & & 1 & 4 & 2 & 3 & & 1 & 14 \\
\hline $\begin{array}{l}\text { Teoria controle das emo- } \\
\text { ções e história da educação }\end{array}$ & & & & & & 1 & & 1 & & & & & & & 2 \\
\hline $\begin{array}{l}\text { Ensino: a distância, reli- } \\
\text { gioso, história, agrícola, } \\
\text { biologia }\end{array}$ & & & & & & 1 & 1 & 3 & & & 1 & & & & 6 \\
\hline História do livro, leitura & & & & & & 1 & & & & & & 1 & 2 & & 4 \\
\hline $\begin{array}{l}\text { Filosofia da educação: } \\
\text { Ética, Kant }\end{array}$ & & & & & & 2 & & & & & & & & & 2 \\
\hline Educação em Piracicaba & & & & & & & 1 & & & & & & & & 1 \\
\hline
\end{tabular}

7 Locais e universidades que sediaram edições dos SIPCs: FEF/UNICAMP, Campinas/SP (1996; 1997; 1999; 2007); PPGE/UNIMEP, Piracicaba/SP (1998; 2003); PPH/UFPR, Curitiba/PR (2000); UNESP, Assis/SP (2001); PPGE/UFPB, João Pessoa/PB (2004); UTFPR, Ponta Grossa/PR (2005); UBA, Buenos Aires/AR (2008); PPGE/UFPE, Recife/PE (2009); UNAL, Bogotá/CO (2010); PPGED/UFGD, Dourados/MS (2012); UNAM, Cidade do México/MX (2014); PPGE/UFES, Vitória/ES (2016). 


\begin{tabular}{|c|c|c|c|c|c|c|c|c|c|c|c|c|c|c|c|}
\hline $\begin{array}{c}\text { Assuntos artigos/Edição } \\
\text { SIPC }\end{array}$ & I & II & III & $I V$ & $V$ & $V I$ & VII & VIII & $I X$ & $X$ & $X I$ & $X I I$ & XIII & $X I V$ & Total \\
\hline $\begin{array}{l}\text { Institucionalização escolar e } \\
\text { civilidade }\end{array}$ & & & & & & & 1 & 2 & 2 & 3 & 4 & 5 & 2 & 8 & 27 \\
\hline $\begin{array}{l}\text { Educação dos senhores de } \\
\text { engenho }\end{array}$ & & & & & & & 1 & & 1 & & & & & & 2 \\
\hline $\begin{array}{l}\text { Práticas e saberes educa- } \\
\text { tivos }\end{array}$ & & & & & & & & 2 & 1 & & & 1 & & 2 & 6 \\
\hline $\begin{array}{l}\text { Educação popular, comuni- } \\
\text { tária, EJA }\end{array}$ & & & & & & & & 2 & & & & 1 & & 1 & 4 \\
\hline Violência na escola & & & & & & & & 1 & & 2 & 3 & 2 & 2 & 1 & 11 \\
\hline $\begin{array}{l}\text { Educação feminina no séc. } \\
\text { XIX }\end{array}$ & & & & & & & & & & & 1 & & & & 1 \\
\hline Educação na corte, império & & & & & & & & & 1 & & & & 1 & & 2 \\
\hline $\begin{array}{l}\text { Educação Tecnológica, } \\
\text { Ciências }\end{array}$ & & & & & & & & & 2 & & & 1 & & & 3 \\
\hline Educação dos nativos & & & & & & & & & & 1 & & & & & 1 \\
\hline $\begin{array}{l}\text { Exxito e fracasso escolar na } \\
\text { perspectiva sociológica }\end{array}$ & & & & & & & & & & 1 & & & & & 1 \\
\hline $\begin{array}{l}\text { Educação como monopólio } \\
\text { do Estado }\end{array}$ & & & & & & & & & & 1 & & & & & 1 \\
\hline Família, escola e Sociedade & & & & & & & & & & 1 & 2 & 2 & & 3 & 8 \\
\hline Educação biocêntrica & & & & & & & & & & & 2 & & & & 2 \\
\hline $\begin{array}{l}\text { Educação profissional, } \\
\text { docente }\end{array}$ & & & & & & & & & & & 3 & & 2 & & 5 \\
\hline $\begin{array}{l}\text { Reforma educativa na } \\
\text { Colômbia }\end{array}$ & & & & & & & & & & & 1 & & & & 1 \\
\hline $\begin{array}{l}\text { Abordagem figuracional } \\
\text { e História da formação } \\
\text { docente }\end{array}$ & & & & & & & & & & & & 1 & & & 1 \\
\hline $\begin{array}{l}\text { Análises sociais, políticas e } \\
\text { escola pública }\end{array}$ & & & & & & & & & & & & 1 & 1 & & 2 \\
\hline $\begin{array}{l}\text { Civilização das crianças e } \\
\text { dos professores na escola }\end{array}$ & & & & & & & & & & & & 1 & & 1 & 2 \\
\hline $\begin{array}{l}\text { Educação, direitos, inclusão } \\
\text { e P. Civilizador }\end{array}$ & & & & & & & & & & & & & 2 & 2 & 4 \\
\hline $\begin{array}{l}\text { Educação, Psicogênese e } \\
\text { Sociogênese }\end{array}$ & & & & & & & & & & & & & 2 & & 2 \\
\hline $\begin{array}{l}\text { Regulação de condutas, } \\
\text { emoções nos espaços es- } \\
\text { colares }\end{array}$ & & & & & & & & & & & 1 & & & 1 & 2 \\
\hline Migração estudantil & & & & & & & & & & & & & & 2 & 2 \\
\hline $\begin{array}{l}\text { Habitus na educação in- } \\
\text { fantil }\end{array}$ & & & & & & & & & & & & & & 1 & 1 \\
\hline $\begin{array}{l}\text { Militares na educação } \\
\text { pública }\end{array}$ & & & & & & & & & & & & & & 1 & 1 \\
\hline $\begin{array}{l}\text { Memórias de professoras, } \\
\text { envelhecer }\end{array}$ & & & & & & & & & & & & & & 1 & 1 \\
\hline $\begin{array}{l}\text { Conhecimento e Julio } \\
\text { Garavito }\end{array}$ & & & & & & & & & & & & & & 1 & 1 \\
\hline 36 & 0 & 0 & 3 & 0 & 0 & 13 & 16 & 12 & 12 & 18 & 20 & 21 & 14 & 30 & 159 \\
\hline
\end{tabular}

Fonte: Anais dos SIPCs (1996-2012). Quadro elaborado pelo autor. 
No Quadro 2, visualiza-se um conjunto de assuntos sobre educação abordados e distribuídos por edições de cada SIPC, entre eles: instituição de ensino, violência escolar, protestantismo, literatura, família, infância, comportamentos de escolares, políticas públicas, educação popular. Destaca-se que os assuntos foram registrados na planilha na medida das ocorrências durante o processo de mapeamento, por isso não houve a preocupação de organizar os dados em ordem (de)crescente, alfabética ou numérica.

Revela-se que a temática educação consolidou um lugar expressivo no conjunto de produções disseminadas nos Anais dos SIPCs. Pode-se afirmar que os fenômenos, os acontecimentos e as experiências humanas educativas, escolarizadas ou não, embora sem centralidade nas obras de Norbert Elias, podem ser interpretadas à luz da Teoria dos Processos Civilizadores, da Sociologia Figuracional e da Teoria Simbólica.

O conjunto de textos analisados indica que o constructo teórico eliasiano provoca o entendimento das dinâmicas históricas e sociais, tendo como fulcro as relações entre indivíduos interdependentes vivendo em sociedade, pois, para Elias, estão articuladas as mudanças no comportamento dos indivíduos e as mudanças na sociedade. Assim, em nosso entendimento, os processos de educação dos indivíduos podem revelar as estruturas da psique humana, as estruturas da sociedade humana e as estruturas da história humana. Isso se forem estudadas em conjunto e em movimento processual, sem isolamentos sociais e históricos.

No que diz respeito à história da educação, identificaram-se textos sobre os assuntos: institucionalização escolar, educação protestante, educação na Idade Média, educação na Colônia e no Império português, educação dos nativos, (auto)controle das emoções e monopólio do Estado no processo escolarizador, memórias das experiências educativas, entre outros. Para a interpretação histórica, as obras mais referenciadas nos textos são $O$ processo civilizador (volume 1 e 2) e A sociedade de Corte. Os conceitos operatórios de maior destaque são o de civilização, (con)figuração, processos sociais, poder, psicogênese, sociogênese, controle das pulsões, Estado moderno. Parte desses conceitos será apresentada nos tópicos seguintes, tendo como referência uma agenda de pesquisa em história da educação por nós empreendida.

\section{INSTITUIÇÃO ESCOLAR: FIGURAÇÃO E MONOPÓLIO DO ESTADO}

A teoria de Norbert Elias nos provoca a pensar (HONORATO, 2009; 2011) como as instituições sociais, particularmente as escolares, tornaram-se fundamentais na produção e na circulação cultural de saberes elementares no século XIX e início do XX na realidade brasileira. A escola como instituição produtora e representante de referenciais civilizatórios apresenta-nos, desde logo, entre outras, uma inquietação: na perspectiva de Norbert Elias, o que pode ser considerado por instituição social? Para problematizar, por ora, focaremos principalmente o conceito de figuração e a questão do Estado moderno como monopolizador de algumas regulações, entre elas, a dos saberes escolarizados.

Como primeiro registro, uma instituição social está fundada nas complexas relações entre indivíduos e sociedade, mais especificamente, com a crescente especialização dos 
indivíduos no tempo e no espaço dos processos civilizatórios. Isso não significa que as instituições sociais, como a religiosa, financeira, jurídica, política, escolar, científica estão traçando caminhos autônomos e livres de qualquer restrição humana. Ou ainda, estão conformadas no sentido althusseriano como aparelhos ideológicos de Estado reprodutores das crenças dominantes. Em outro sentido, as instituições estão condicionadas pelos indivíduos em sociedade a desenvolverem um grau bastante elevado de regulações sociais interdependentes com autorregulações dos homens estabelecendo um ideal de comportamento social.

Em instituições, os indivíduos vivem dinâmicas relacionais e tensões produtoras de controles sociais e autocontroles pessoais que vão se sedimentando nas interações coletivas e produzindo identidades, autoimagens, culturas, comportamentos, habitus e disputas de poder. As instituições sociais são, numa acepção de Norbert Elias (1980), figurações dinâmicas que se referem essencialmente a seres humanos interdependentes formando, uns com os outros, um emaranhado flexível de tensões e comportamentos comumente formalizados e institucionalizados demarcando especificidades e pertinência para a constituição de grupos, cidades, Estados e nações.

Pensar de maneira interdependente instituições, indivíduos e sociedade, no interior de um tempo e espaço, significa identificar e analisar os acontecimentos sem estabilizá-los como estruturas superiores e sem perder a dimensão dos longos processos humanos. Logo, as instituições são figurações específicas e dialógicas com o estágio do processo civilizador de uma dada sociedade constituída de longos passados conflituosos e futuros distantes, incertos.

Embora as instituições escolares não compusessem as preocupações centrais da Teoria dos Processos Civilizadores, em sua obra-prima, O processo civilizador, Norbert Elias (1993; 1994a), ao elaborar os estágios de desenvolvimento de uma civilização, nos permite sistematizar: 1) os processos educativos, institucionalizados ou não, têm centralidade em qualquer civilização, isso porque há uma constante que é a aprendizagem de comportamentos, tanto no plano individual quanto no social, transmitida de uma geração para outra, podendo se transformar em um habitus (segunda natureza); 2) a formulação e incorporação dos valores educativos como habitus implicam efetivas mudanças de conduta e sentimentos rumo a uma direção específica, maior controle social e autocontrole das emoções dos indivíduos; 3 ) o (auto)controle das emoções, bem como, dos saberes populares e científicos, fomenta um crescente processo de individualização no social, e esse processo passou a ser cada vez mais potencializado e assegurado por grupos e instituições específicas, no caso, a escolar; 4) a escolarização dos indivíduos tornou-se então obrigatória, e, assim, na estruturação da modernidade, a regulação dos saberes elementares fora monopolizada pelo Estado-nação como um dos fundamentos de sua existência, assim como aconteceu com o controle legítimo do uso da força física e da arrecadação tributária.

No curso de organização dos Estados-nação houve um movimento diferenciado nos procedimentos de coerção externa e autocoerção, segundo Veiga (2013), nesse ponto a obrigatoriedade escolar no século XIX passa a ter força e ser pensada no campo dos direitos sociais.

O processo de institucionalização da escola no Ocidente aos poucos incluiu a 
obrigatoriedade da frequência à escola como fundamental para a consolidação da educação escolar como parte da ordenação nacional. Ao longo do século XIX, de um modo ou de outro, todas as nações apresentaram a obrigatoriedade como lei (VEIGA, 2013, p. 135).

No Brasil, a institucionalização da obrigatoriedade e da gratuidade escolar, para universalizar os saberes elementares ao povo, foi uma preocupação estruturada inicialmente em termos legais na primeira metade do período oitocentista no Regime Imperial. ${ }^{8} \mathrm{O}$ fato é que a promulgação de prescrições legais imperiais - o Ato Adicional à Constituição de 1824 que define a gratuidade da instrução primária a todos os cidadãos (BRASIL, 2001a), a Lei de 15 de outubro de 1827 que estabelece a criação de escolas de primeiras letras que fossem necessárias em cidades, vilas e lugares mais populosos (BRASIL, 1827) e o Ato Adicional de 1834 que transfere para as províncias a competência de legislar sobre instrução pública primária e secundária (BRASIL, 2001b) - ocorreu em concomitância com a estruturação constitucional do Estado monárquico e, mais tarde, oficialmente a partir de 1889, com a formação e estruturação do Estado republicano brasileiro.

Considera-se então aqui a instrução pública institucionalizada como um dos monopólios presentes na formação do Estado brasileiro. As escolas federais, provinciais e/ou municipais do século XIX representaram um lugar civilizatório para inserir o povo na vida em sociedade idealizada por grupos estabelecidos em termos educativos, socioculturais, políticos e religiosos. Nelas, as pessoas produziriam e colocariam em circulação a autoimagem de ser civilizado para sua época ao considerar as tensões vividas: manutenção e abolição da escravidão; trabalho escravo e trabalho livre; vida rural e vida urbana; senadores vitalícios e eleitos pelas províncias; voto distrital e voto popular, grupos conservadores e grupos liberais; Monarquia e República, entre outras.

Com a monopolização do ensino pelo Estado, a ação educativa empreendida pelos indivíduos passa a ter centralidade na generalização do discurso da suposta inclusão daqueles tradicionalmente segregados da sociedade dita civilizada. Por conseguinte, a instrução pública deveria estar em nome do ato de civilizar e, com isso, estenderia à população a imagem de um "nós brasileiro", a partir dos modelos de produção de comportamentos autorregulados, socializados e difundidos por meio da cultura escrita, dos saberes elementares, das ciências e do imaginário de nação. Contudo, no final do século XIX e início do XX, os brasileiros viviam problemas considerados travas ao progresso nacional, como: falta de saneamento básico, epidemias como a febre amarela, vícios como alcoolismo e tabagismo, alto índice de analfabetismo - 82,6\%, conforme o Censo Brasileiro de 1890 (BRASIL, 1890) -, entre outros.

Para colaborar no enfrentamento dos problemas de ordem civilizatória, a educação escolarizada como o monopólio do Estado era uma saída e por isso deveria ser reformulada. Na realidade brasileira, uma solução paliativa foi investir na criação de escolas elementares

8 Sobre a obrigatoriedade escolar no Brasil, em diferentes Estados, consultar a coletânea organizada por Vidal, Sá e Silva (2013). 
de ensino mútuo (BASTOS \& FARIA FILHO, 1999), na criação de escolas normais para formar professores para o magistério primário (HONORATO, 2011) e, no último quartel do século XIX, na criação da escola graduada no formato de grupos escolares (SOUZA, SILVA \& SÁ, 2013); ainda, havia a coexistência de mestres-escolas, escolas isoladas, escolas rurais, escolas confessionais e privadas - as duas últimas, mesmo tendo financiamentos particulares, também seguiam os dispositivos legais ofertados pelo Estado.

\section{ESCOLA DE FORMAÇÃo DE PROFESSORES: INDIVÍDUOS DA AÇÃO CIVILIZATÓRIA}

Na sociedade brasileira do século XIX os representantes do Estado e das entidades civis, objetivando estruturar uma espécie de monopólio de instrução escolar, compreendiam a escolarização dos indivíduos como lugar de mudança das crenças, mentalidades, comportamentos e dos rumos da organização social, política, cultural e econômica. Assim, para garantir aos filhos do povo a oferta da escolarização elementar, carecia também criar instituições voltadas à preparação daqueles incumbidos em reger as ações educativas civilizatórias. Estamos a falar das escolas normais de formação de professores. ${ }^{9}$

Compreender as escolas normais como figurações constituídas de indivíduos da ação civilizatória e em civilização (HONORATO, 2011;2014) foi um dos ângulos de análise que as teorias de Norbert Elias nos provocaram. É um desafio observar e interpretar as instituições escolares tendo como referência as dinâmicas relacionais travadas pelos indivíduos, para isso torna-se fundamental pesquisar os comportamentos previstos nos dispositivos normativos e os comportamentos vividos no cotidiano escolar, objetivando identificar os deveres, as tensões, gradientes de poder, controles sociais, autocontrole das emoções e sentimentos de seres tidos como civilizados na vida em sociedade.

Tomando como caso de pesquisa a realidade das escolas de formação de professores do Estado de São Paulo, período entre 1896 e 1913, quando existiram dois modelos interdependentes de instituições - a escola normal e a escola complementar - para diplomar professores, pôde-se inferir que nominalmente foram prescritos comportamentos ao pessoal administrativo, ao pessoal docente e aos alunos, todos aqui considerados indivíduos das ações civilizatórias (HONORATO, 2014).

O pessoal administrativo regimentalmente foi composto por diretor, auxiliar de diretor, secretário, amanuense/arquivista, bibliotecário, preparador de laboratório de física e de química, zelador de museu pedagógico, professora-inspetora, porteiro, contínuo, jardineiro, servente para a sessão feminina e para a masculina (SÃO PAULO, 1896a; 1896b; 1912; 1913). A esse grupo, em geral, competia organizar os espaços pedagógicos, zelar pelo patrimônio material, escriturar as atividades administrativas, relatar atividades para as autoridades superiores, zelar pela disciplina interna do estabelecimento chamando com

9 No Brasil, do Império à República, emergiram escolas normais nas diferentes unidades federativas: 1835, Niterói/RJ; 1836, Salvador/BA; 1842, Cuiabá/MT; 1846, São Paulo/SP; 1864, Teresina/PI; 1869, Porto Alegre/RS; 1870, Curitiba/PR; 1870, Aracaju/SE; 1873, Vitória/ES; 1873, Natal/RN; 1878, Fortaleza/CE; 1880, Rio de Janeiro/RJ; 1880, Florianópolis/SC; 1883, João Pessoa/PB; 1884, Goiás/GO; 1890, São Luís/MA; entre outras (Cf.: ARAUJO, FREITAS \& LOPES, 2008). 
urbanidade e polidez à ordem aqueles que dela se afastassem. Em destaque, com maior gradiente de poder, o diretor tinha reconhecimento em decorrência de seu prestígio com os estratos superiores burocráticos e políticos do Estado, bem como, de seu prestígio junto aos seus representados, e da sua moralidade diante da representação da sociedade local. Portanto, o pessoal administrativo representara uma divisão social do trabalho escolar avançada e com alta regulamentação, com o intuito de potencializar um processo escolarizador que demandasse a especialização de administradores da cultura escolar.

Ao pessoal docente competia treinar os professorandos a ensinar nas escolas primárias. Os seus gradientes de poder na relação com o pessoal administrativo e com o grupo de alunos consistiriam em: a) domínio de saberes científicos e métodos de ensino a serem transmitidos; b) autonomia e habilidade de planejar e aplicar exercícios referentes às matérias ministradas; c) conhecimento sobre a situação de sala de aula; d) fornecimento ou sonegação ao diretor de informações tácitas do fazer pedagógico; e) participação nos exames de suficiência de candidatos à matrícula, nos quais a arguição oral era de sua responsabilidade, sob a supervisão do diretor; f) acesso às famílias para entregar as notas de aplicação e comportamentos de cada aluno; g) registro de comparecimento tardio e de retirada dos alunos na sala de aula; h) atribuição de notas de aplicação e comportamentos dos alunos.

$\mathrm{Na}$ relação com os alunos, os professores desempenhariam o papel de agentes civilizadores ao disseminarem saberes formalizados, cultura moral, urbanidade, civismo, preceitos higiênicos, disciplina, entre outros. Como agentes civilizadores, se voltariam à formação do caráter do aluno rumo a comportamentos autorregulados para novos desafios e patamares de civilidade, a serem futuramente transmitidos aos alunos das escolas primárias.

Os professorandos tinham geralmente entre 14 e 21 anos de idade, além do processo de ensino e aprendizagem a ser incorporado para o exercício da futura carreira no magistério, para eles também eram imprescindíveis orientações de "boas maneiras":

Artigo 15. - Os alunos deverão comparecer à Escola trajando decentemente, mas sem luxo e observar em sua conduta os seguintes preceitos:

a) Proceder sempre com urbanidade;

b) Prestar a devida atenção aos exercícios e lições;

c) Atender com docilidade às recomendações e aos Conselhos dos professores e funcionários da Escola;

d) Tratar com boas maneiras os seus colegas;

e) Comparecer pontualmente às aulas e exercícios, não se ausentando sem anuência do diretor ou professor;

f) Não danificar os objetos escolares (SÃO PAULO, 1912, p. 3).

Nota-se que o desenvolvimento de condutas civilizadas dos alunos para relações com professores, pessoal administrativo, família e colegas da escola assume importante lugar nas orientações pedagógicas do final do século XIX e início do XX. Todavia, os alunos não eram desprovidos de gradientes de poder, até mesmo porque eles eram essenciais à vida das escolas complementares e normais, principalmente, a razão da existência delas. Sem os alunos, no mínimo, os grupos administrativo e docente não teriam sentido profissional e relacional. 
Em síntese, o estudo (HONORATO, 2014) inferiu que a formação de professores nas escolas paulistas era administrada por um grupo de indivíduos produtores de relações de interdependência fundadas numa hierarquia e burocracia. Nas figurações administrativas, cada indivíduo vivenciava tensões entre a autonomia para desempenhar sua ocupação funcional e o forte controle proposto pelo Estado, materializado pelas estratégias de distribuição de poder em diferentes níveis e dirigidas pelo diretor, autoridade superior. Nas figurações docentes, havia o rigoroso controle que objetivava comportamentos mais autocontrolados rumo à mudança de costumes no trabalho do professor, cada vez especializando mais o fazer pedagógico. Nas figurações do alunado, os princípios de "boas maneiras" deveriam ser cultivados na instituição escolar, e estendidos à vida em sociedade. Tais inferências dão sentido à noção de indivíduos da ação civilizatória nas figurações escolares.

\section{RELAÇÕES DE PODER}

Tendo como referência o entendimento de instituição escolar como figuração social, de indivíduos e suas individualizações em ações civilizatórias e de que o cotidiano escolar se apresenta repleto de relações interpessoais não harmônicas, o conceito de poder proposto por Norbert Elias também vem contribuindo com os nossos estudos no campo da história da educação (HONORATO, 2008; 2011; 2015).

Sumariamente, conforme Norbert Elias (1980), poder:

a) "não é um amuleto que um indivíduo possua e o outro não; é característica estrutural das relações humanas - de todas as relações humanas" (ELIAS, 1980, p. 81. Grifo do autor);

b) é fonte, recurso e capacidade que dizem sobre o nível de dependência que um indivíduo tem relativamente com o outro (por exemplo, conhecimento, força física, coesão de grupo, parentesco). É inexplicável simplesmente como econômico, político ou militar, isto é, como propriedade única;

c) é instável, distribui-se conforme o movimento das figurações sociais, estando sempre em uma balança de diferentes gradientes, que pode inverter-se em qualquer curso da história, dependendo do nível de acesso às suas proporções por parte dos indivíduos;

d) como equilíbrio não é sinônimo de igualdade de forças, está presente onde quer que haja uma democratização funcional entre pessoas, grupos, instituições e sociedades;

e) é relação de tensão entre duas (ou mais) tradições culturais em uma dinâmica entre si, pois "de um modo geral, as relações humanas, [são] pelo menos bipolar[es] e, usualmente multipolar[es]" (ELIAS, 1980, p. 80);

f) é função das interdependências. O indivíduo tem poder sobre o outro, desde que este lhe atribua qualquer tipo de valor (por exemplo, relação pai e filho, escravo e senhor, professor e aluno etc.); e

g) como característica estrutural de relações humanas não porta sentido de polarizações, como bem ou mal, dominado ou dominante. Quando há grandes diferenças de poder e a superioridade faz-se prevalecer com muita força nas relações, pode promover alto grau de estigmatização, fixando o sentimento de 'valor humano inferior' (ELIAS \& SCOTSON, 2000). 
Com o conceito de poder, produzimos um estudo intitulado Indisciplina, poder y civilidad: el libro negro de los futuros professores (HONORATO, 2008). Uma das proposições foi pensar a cultura escolar assumindo como lente a indisciplina dos alunos em formação de professores na Escola Complementar de Piracicaba do Estado de São Paulo, entre o período de 1896 e 1911. Para tanto, tivemos como fonte histórica o livro de registros de imposição de penas e buscamos substituir a oposição disciplina versus indisciplina pela concepção de disciplina $e$ indisciplina em interdependência.

Um argumento produzido foi o de que o uso do regulamento disciplinar para reprimir a indisciplina do estudante, por meio das aplicações de penas, tornou-se fundamental para racionalizar o cotidiano escolar e provocar na psique dos futuros professores a interiorização progressiva dos impulsos, das emoções e dos constrangimentos, alterando os seus sentimentos de medo e vergonha numa direção de comportamentos mais (auto)controlados. A dinâmica disciplina exigida e indisciplina praticada revelam tensões nas quais as relações entre os indivíduos da ação civilizatória no cotidiano escolar se apresentam segundo $\mathrm{o}$ acesso às fontes de poder e seus (des)equilíbrios.

Em outro estudo (HONORATO, 2015), à luz do conceito de poder, trouxemos para a história da educação um debate a respeito da formação de professores no Estado de São Paulo no período entre 1897 e 1921, tensionando os modelos da escola normal e da escola complementar. A argumentação central consistiu em que os modelos produziram menos dualidades na formação de professores (ANTUNHA, 1976; TANURI, 1979) e mais interdependências entre pessoas, constituindo figurações específicas e disputas visíveis em uma metafórica balança de poder. Em outras palavras, se, no final do século XIX e início do XX, a balança de poder pendia para a Escola Normal da capital de São Paulo, no avançar do percurso histórico a diferença de poder foi sendo reduzida, alterando o curso da balança na direção das congêneres complementares, normais primárias e normais secundárias localizadas no interior do Estado, tendo entre elas uma culminância de equilíbrio de poder em 1921, quando todas passaram, por meio de equiparação, para instituições de um tipo único: escolas normais. Situação, evidentemente, que não significou igualdade de poder por parte dos indivíduos constituintes das figurações.

Para tanto, fora fundamental compreender as ações educativas, pedagógicas, culturais e políticas desenvolvidas pelos indivíduos das escolas complementares e normais (professores, alunos, pessoal do administrativo e lideranças citadinas), bem como compreender os movimentos reformadores da instrução pública liderados por Oscar Thompson, na Reforma de 1911, e por Sampaio Dória, na Reforma de 1920.

Tomando como caso específico, em torno da Escola Normal de Piracicaba, na transição dos anos de 1910 para os de 1920, constituiu-se uma figuração de professores representada por Honorato Faustino, Manoel Bergström Lourenço Filho, Dário Brasil, Fabiano Lozano, Pedro Crem Filho, Antônio Pinto de Almeida Ferraz, Sud Mennucci, Thales Castanho de Andrade e outros que produziram um tempo e um lugar piracicabano de efervescência sociocultural, pedagógica, artística e política (HONORATO, 2017). 
Os professores foram reconhecidos como intelectuais, literatos, compositores, pintores, musicistas, educadores e políticos, receberam, elogiosamente do escritor José Maria Ferreira, o título de bloomsburry ${ }^{10}$ caipira. Nas evidências de Hilsdorf, no texto intitulado Lourenço Filho em Piracicaba, o impacto do grupo de professores fora notável em diferentes esferas:

\begin{abstract}
Vários dos bloomsburryanos estavam já espalhados por outras cidades, trabalhando como professores, redatores de jornais e críticos, fazendo literatura, gravitando ao redor... de Monteiro Lobato na 'Revista do Brasil' e da redação do 'O Estado de S. Paulo'! 'Não se fala do perigo amarelo. Há outro, muito mais próximo. Falo do perigo piracicabano", teria dito Lobato a propósito das "hordas de jovens literatos piracicabanos, todos saídos da Escola Normal, que procuravam a Revista querendo publicar seus textos e assim iniciar uma carreira na crítica, na literatura e no jornalismo', segundo J. M. Ferreira (HILSDORF, 2003, p. 102).
\end{abstract}

O impacto e os gradientes de poder da figuração de professores passavam também pela relação com o Sampaio Dória, liderança reformadora da instrução pública paulista em 1920/1921 e referência da Liga Nacionalista Paulista, também nucleada em Piracicaba. Tal grupo sistematizou e disseminou em esfera local e estadual práticas renovadoras voltadas à formação de professores, entre elas a questão da autonomia didática, do ensino ativo, do plano de prática pedagógica, da república escolar, do escotismo, do clube da horta, entre outras. Essas inovações são evidenciadas nos textos publicados na Revista de Educação (FAUSTINO, 1921a; 1921b; 1922a; 1922b; 1922c; 1923), órgão da Escola Normal de Piracicaba e Anexas, que era também uma fonte de poder do grupo de professores em tela ligado aos reformadores da instrução em 1920, momento de reequilíbrio de poder.

\title{
INTELECTUAIS DA EDUCAÇÃo
}

Considerando o nosso aprofundamento nos estudos históricos sobre a formação de professores em escolas normais paulistas e as contribuições da matriz interpretativa proposta por Norbert Elias, passamos também a pesquisar a história de personagens da educação. A premissa foi que a história dos educadores intelectuais diz respeito ao entrecruzamento do pedagógico, cultural, político, artístico e das relações interpessoais nas instituições, e por isso, segundo Vieira (2008), ao campo da história da educação é cada vez mais pertinente o diálogo com as teorias sociais.

O nosso educador intelectual eleito foi o Honorato Faustino (1904-1930). ${ }^{11}$ Ele nasceu em Itapetininga/SP, em 1867, morreu na cidade de São Paulo, em 1948, foi normalista diplomado na capital paulista, em 1889, e formado em medicina pela Faculdade de Curitiba/

10 Bloomsburry: bairro londrino que no início do século XX ficou conhecido pelo grupo de escritores, pintores e intelectuais que se reuniam em suas praças, jardins e casas vitorianas, entre eles: Virginia Woolf, sua irmã Vanessa Bell, E. M. Foster, Katherine Mansfield, T. S. Eliot, Máximo Gorki (Bloomsburry..., 2009, p. 4-6).

11 A pesquisa sobre Honorato Faustino (1904-1930) é o resultado do nosso pós-doutorado em Educação (20142015), realizado na Faculdade de Filosofia e Ciências da Universidade Estadual Paulista (FFC/UNESP, Campus Marília/SP), com bolsa PNPD/CAPES, sob orientação da Prof ${ }^{\mathrm{a}}$. Dr ${ }^{\mathrm{a}}$. Ana Clara Bortoleto Nery. 
PR, em 1920. Ele foi diretor e lente da Escola Complementar e Normal de Piracicaba/SP, ficou à frente do cargo, em um tempo que havia muitas remoções de ofício, durante 24 anos, entre 1904 e 1928. Em 1909, foi conselheiro da Santa Casa de Misericórdia de Piracicaba, na gestão do Barão de Rezende. No início da década de 1910, foi membro fundador da Universidade Popular de Piracicaba (U.P.P.) e maestro musical da mesma. Em 1928, ele mudou para a cidade de São Paulo, onde dirigiu a Escola Normal da capital, localizada na praça da República, estabelecimento considerado como referencial pedagógico e como irradiador de políticas de formação de professores; lá Honorato Faustino aposentou-se em 1930.

Ao longo de sua trajetória, Honorato Faustino como autor escreveu contos de refinado gosto literário, músicas pedagógicas, métodos de ensino de língua portuguesa e artigos publicados em jornais. Ainda, estreitou relações com o professor e reformador Sampaio Dória no contexto da Liga Nacionalista nucleada em Piracicaba/SP e na Reforma Educacional Paulista de 1920. Destaca-se que, para diplomação dos normalistas da turma de 1920, Sampaio Dória fora convidado como conferencista central:

\footnotetext{
Escola Normal: As festas de formatura - Sessão solenne no Theatro Santo Estevam - Conferencia do Sr. dr. Sampaio Dória - Outras notas.

No palco, à mesa, ao lado do sr. dr. Honorato Faustino de Oliveira, director da Escola Normal, tomaram lugar o sr. dr. A. Sampaio Dória, Director Geral da Instrucção Pública e o sr. Coronel Fernando Febiliano da Costa, governador da cidade, que paranymphou a turma, e corpo docente da Escola Normal.

Iniciando-se o programma, foi cantado pelos professorando o Hymno da Escola Normal, letra de João Lourenço Rodrigues e música de Lazaro R. Lozano.

O dr. Honorato Faustino, abrindo a sessão deu a palavra ao dr. Sampaio Doria que leu sua conferencia [...] (ESCOLA, 1920, p. 1).
}

Aventa-se a hipótese que, a par das relações de interdependências de Sampaio Dória com Lourenço Filho e demais professores, o diretor Honorato Faustino foi um dos principais articuladores da execução da Reforma da Instrução Pública em Piracicaba. Honorato Faustino também fora considerado como homem do progresso educacional, moral, intelectual e cultural; detinha a imagem de ilustrado, de cidadão cônscio, de cabedal científico, de dedicado cultor de belas letras e artes e de competente pela seriedade que dirigia os estabelecimentos de ensino e pela formação de mestres de reconhecida habilidade intelectual.

A pesquisa sobre Honorato Faustino apropriou-se da discussão feita por Norbert Elias (1995), na obra Mozart: sociologia de um gênio. Nesse livro, Elias apresenta reflexões sociológicas a respeito da vida do músico Wolfgang Amadeus Mozart (1576-1791) e sistematiza o conceito de gênio como um indivíduo social que sabe fazer coisas que a grande maioria das pessoas não consegue, isto é, um ser humano excepcionalmente dotado e altamente individualizado no social, nas tensões oriundas da relação indivíduo e sociedade de sua época que indicam obras resultantes como algo social e não inato.

A partir da noção de gênio e a trajetória do nosso personagem Honorato Faustino, pôde-se elaborar que uma investigação sobre a trajetória histórica de um educador intelectual implica em: a) compreender a produção da singularidade na experiência social; b) perceber 
os desejos do indivíduo e a internalização e a externalização dos controles sociais expressas nas obras resultantes dos processos intelectuais; c) apresentar a existência de tensões entre o indivíduo e os laços sociais no esforço de reconhecimento público; d) mapear os problemas encontrados pelo indivíduo durante a sua produção e circulação intelectual; e) dimensionar os comportamentos apresentados e os seus impactos numa figuração social específica; f) identificar as fontes de poder do indivíduo na relação de interdependência com o outro, almejando interpretar relações entre establishment e outsiders - essa relação trata-se de uma estrutura que dá a certos grupos, tidos como superiores, fontes maiores de poder na relação com os seus diferentes que passam a viver tensões muitas vezes estigmatizantes.

Os fundamentos descritos possibilitaram a estratégia de problematizar o papel de um educador intelectual numa figuração escolar específica e num cenário educacional geral, de entendê-lo como produtor de capital simbólico (BOURDIEU, 2000) e de pensá-lo como um proponente, organizador e dirigente de uma cultura escolar (JULIA, 2001). Bem como, não se seguiu uma pesquisa histórica que concebesse uma vida como sequência de fatos e episódios, trajetórias repletas de sucessões e sem tensões. Ou, como chamou Bourdieu (2008), a ilusão biográfica.

\section{CONSIDERaÇões Finais}

Este manuscrito apresentou conceitos das teorias de Norbert Elias que têm contribuído com a nossa agenda de pesquisa no campo da história da educação. Foram privilegiados os conceitos de figuração, de Estado moderno, de indivíduo, de sociedade, de interdependência, de poder e de intelectual. Tais fundamentos nos possibilitaram interpretações sobre a história das instituições escolares como monopólios do Estado, das escolas de formação de professores como figurações de relações de poder e das trajetórias de educadores intelectuais como um entrecruzamento do pedagógico, cultural, político, artístico e social. Os temas abordados recaíram sobre a sociedade brasileira do século XIX e início do XX, mais particularmente a respeito da realidade do Estado de São Paulo.

Para finalizar, distante da pretensão de expor e esgotar todas as possibilidades de leitura da história da educação a partir da matriz interpretativa eliasiana, propõe-se aqui tecer ainda duas considerações: a primeira diz respeito à intersecção entre o campo da História e da Sociologia, e por extensão da História da Educação; e, a segunda versa sobre alguns limites da obra do autor em tela.

No livro $A$ sociedade de corte, Norbert Elias (2001b) questiona as pesquisas históricas de sua época preocupadas em julgar o passado a partir de padrões e princípios ideológicos do presente, tornando as relações sociais idas incompreensíveis e, no mesmo movimento, questiona também as pesquisas sociológicas focadas nas relações sociais aprisionadas em estruturas supra-humanas e sem considerar a historicidade de longo tempo dos acontecimentos. Ao tecer críticas às ciências da Sociologia e da História, Elias propõe-se a pensar e sistematizar problemáticas sociológicas para a História e problemáticas históricas para a Sociologia. Isso não significaria a fusão das duas ciências, mas sim possibilitar intersecções 
entre elas, a fim de investigar e analisar uma figuração social de indivíduos interconectada às singularidades outras e às sociodinâmicas de mudanças, continuidades e rupturas numa perspectiva processual e de longa duração.

O arcabouço teórico e metodológico oferecido por Norbert Elias está sintonizado com uma Sociologia e uma História comprometidas em superar os dogmas herdados da metafísica, isto é, das explicações universais e naturais e das análises estrutural-funcionalistas. Para Elias, os processos sociais e as estruturas psíquicas particulares são formados pelos indivíduos, por outros e para os próprios indivíduos. Desse modo, compreendem-se os indivíduos conectados uns aos outros das mais variadas formas, em cadeias de interdependências, formando figurações dos mais diversos tipos, as quais mantêm tensões e relações de poder em processos sociais em sociedade.

Assim, para pensar com Norbert Elias os processos históricos da educação escolarizada, interligados à sociedade e ao indivíduo, torna-se significativo distanciar-se da,

[...] tendência a pensar em termos de causas isoladas, a identificar fatores individuais gerando as transformações sociais, ou quando muito, a examinar apenas o aspecto legal das instituições sociais e a buscar os exemplos, de acordo com os quais foram modelados por este ou aquele agente - tudo isso tornou esses processos e instituições tão inacessíveis ao nosso entendimento como eram os processos naturais para os pensadores escolásticos (ELIAS, 1993, p. 36).

Isto não significa que, na obra de Norbert Elias, pode-se encontrar uma matriz de interpretação historiográfica e sociológica pela qual as figurações escolares ou a sociedade podem ser rigorosamente adequadas ou emolduradas. Mesmo porque Elias não se dedicou aos estudos da educação escolarizada e sua obra não está isenta de limitações.

Chartier (1990), por exemplo, aponta que na obra de Elias há ausência de análise da difusão de modelos de comportamentos em outros grupos sociais além do da corte. Já Burke (2005) menciona que O processo civilizador foi alvo de inúmeras críticas por tratar a civilização como um fenômeno ocidental e ainda que, ao discutir a Idade Média, dedicou-se pouco à Itália. Veiga (2008), ao sistematizar relações entre a sociologia de Elias e a história da educação, compreende que para a análise da sociedade brasileira do século XIX não é possível transpor a experiência dos processos civilizadores europeus, devido, entre outras razões, à permanência da escravidão em longa duração, ao compartilhamento do uso legal da força física entre Estado e senhores de escravos, à colonização dos povos indígenas, às especificidades da aristocracia portuguesa. Já conforme Costa e Menezes (2013), Elias não deve ser, num sentido stricto sensu, considerado um intelectual da Educação, mas sim como um pensador que pode e deve ser estudado pelos pesquisadores do campo da Educação.

Por fim, segundo Goudsblom (2001), um dos desafios para a pesquisa é continuar a pensar com Elias, e não como Elias. Isso implica compreendermos as teorias eliasianas como inacabadas e darmos continuidade à leitura dos processos sociais, culturais e históricos da Educação, em diálogo com os processos civilizadores. 


\section{REFERÊNCIAS}

ANAIS SIPCs. Anais impressos digitalizados e CD-rom eletrônicos do Simpósio Internacional Processos Civilizadores (1996-2012). Volumes 1, 2, 3, 4, 5, 6, 7, 8, 9, 10, 11, 12, 13 e 14. Disponível em < www.uel.br/grupo-estudo/processoscivilizadores $>$. Acesso em 3 de nov. 2017.

ANTUNHA, H. C. G. A Instrução Pública no Estado de São Paulo: a reforma de 1920. São Paulo: EPU, 1976.

ARAUJO, J. C. S.; FREITAS, A. G. B.; LOPES, A. P. C. (Org.). As escolas normais no Brasil: do Império à República. Campinas: Alínea, 2008.

BASTOS, M. H. C.; FARIA FILHO, L. M. (Org.). A escola elementar no século XIX: o método monitorial/mútuo. Passo Fundo: EDIUPF, 1999.

BLOOMSBURRY. Folha de São Paulo. São Paulo, p. 4-6, 30, abr. 2009.

BOURDIEU, P. O poder simbólico. Rio de Janeiro: Bertrand do Brasil, 2000.

BOURDIEU, P. Razões práticas: sobre a teoria da ação. Campinas: Papirus, 2008.

BRASIL. Coleção de leis [da] República Federativa do Brasil. Brasília, DF, v. 8, Col. $1,1890$.

BRASIL. Constituições Brasileiras: 1824. Brasília: Senado Federal e Ministério da Ciência e Tecnologia, Centro de Estudos Estratégicos, 2001a.

BRASIL. Constituições Brasileiras: 1834. Brasília: Senado Federal e Ministério da Ciência e Tecnologia, Centro de Estudos Estratégicos, 2001b.

BRASIL. Lei de 15 de outubro de 1827. Presidência da República, Casa Civil, Subchefia para Assuntos Jurídicos. 1827. Disponível em: $<\underline{\text { http://www.planalto.gov.br/ccivil_03/leis/ }}$

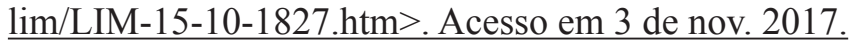

BURKE, P. O que é história cultural? Rio de Janeiro: Jorge Zahar, 2005.

CHATIER, R. A história cultural: entre práticas e representações. Lisboa/Rio de Janeiro: Difel/Bertrand do Brasil, 1990.

COSTA, C. J.; MENEZES, S. L. Norbert Elias e a teoria dos processos civilizadores. Revista HISTEDBR on-line. Campinas, n. 53, 238-262, out., 2013.

ELIAS, N. A sociedade de corte. Rio de Janeiro: Jorge Zahar, $2001 \mathrm{~b}$.

ELIAS, N. A sociedade dos indivíduos. Rio de Janeiro: Jorge Zahar, 1994b. ELIAS, N. Conocimiento y poder._Madrid: La Piqueta, 1994c.

ELIAS, N. Escritos \& ensaios 1: estado, processo, opinião pública. Rio de Janeiro: Jorge Zahar, 2006. 
ELIAS, N. Introdução à sociologia. Lisboa: Edições 70, 1980.

ELIAS, N. Mozart: sociologia de um gênio. Rio de Janeiro: Jorge Zahar, 1995.

ELIAS, N. Norbert Elias por ele mesmo. Rio de Janeiro: Jorge Zahar, 2001a.

ELIAS, N. O processo civilizador: formação do estado e civilização. Rio de Janeiro: Jorge Zahar, v. 2, 1993.

ELIAS, N. O processo civilizador: uma história dos costumes. Rio de Janeiro: Jorge Zahar, v. 1, 1994a.

ELIAS, N. Os alemães: a luta pelo poder e a evolução do habitus nos séculos XIX e XX. Rio de Janeiro: Jorge Zahar, 1997.

ELIAS, N. Sobre o tempo. Rio de Janeiro: Jorge Zahar, 1998.

ELIAS, N. Teoria simbólica. Organização e introdução por Richard Kilminster. Oeiras: Celta Editora, 1994d.

ELIAS, N.; SCOTSON, J. L. Os estabelecidos e os outsiders: sociologia das relações de poder a partir de uma pequena comunidade. Rio de Janeiro: Jorge Zahar, 2000.

ESCOLA Normal: as festas de formatura - sessão solenne no Theatro Santo Estevam conferencia do Sr. dr. Sampaio Dória - outras notas. Jornal de Piracicaba. Piracicaba, v. 21, n. 7.562, 25 de nov. 1920.

FAUSTINO, H. (Org.). Revista de Educação. Piracicaba, Orgam da Escola Normal de Piracicaba e Anexas, v. 1, n. 1, mai., 1921a.

FAUSTINO, H. (Org.). Revista de Educação. Piracicaba, Orgam da Escola Normal de Piracicaba e Anexas, v. 1, n. 2, ago., 1921 b.

FAUSTINO, H. (Org.). Revista de Educação. Piracicaba, Orgam da Escola Normal de Piracicaba e Anexas, v. 2, n. 1, mai., 1922a.

FAUSTINO, H. (Org.). Revista de Educação. Piracicaba, Orgam da Escola Normal de Piracicaba e Anexas, v. 2, n. 2, out., 1922b.

FAUSTINO, H. (Org.). Revista de Educação. Piracicaba, Orgam da Escola Normal de Piracicaba e Anexas, v. 2, n. 3, dez., 1922c.

FAUSTINO, H. (Org.). Revista de Educação. Piracicaba, Orgam da Escola Normal de Piracicaba e Anexas, v. 3, n. 1, set., 1923.

GEBARA, A. Conversas sobre Norbert Elias: depoimentos para uma história do pensamento sociológico. Piracicaba: Biscalchin, 2005.

GEBARA, A. Norbert Elias no Brasil. In: GEBARA, A.; COSTA, C. J.; SARAT, M. (Org.). Leituras de Norbert Elias: processo civilizador, educação e fronteiras. Maringá: EdUEM, 2014, p. 21-34. 
GOUDSBLOM, J. Pensar com Elias. In: GARRIGOU, A.; LACROIX, B. (Org.). Norbert Elias: a política e a história. São Paulo: Perspectiva, 2001, p. 241-247.

HEINICH, N. A sociologia de Norbert Elias. Bauru: Edusc, 2011.

HILSDORF, M. L. S. Lourenço Filho em Piracicaba. In: SOUSA, C. P. História da Educação: processos, práticas e saberes, 3. ed. São Paulo: Escrituras, 2003, p. 95-112.

HONORATO, T. Escola complementar e normal de Piracicaba: formação, poder e civilidade. 2011. f. 241. Tese (Doutorado em Educação Escolar) - Universidade Estadual Paulista Júlio de Mesquita, Araraquara, São Paulo, 2011.

HONORATO, T. Indisciplina, poder y civilidad: el libro negro de los futuros professores. In: KAPLAN, C. V. (Org.). La civilización en cuestión: escritos inspirados en la obra de Norbert Elias. Buenos Aires: Miño y Dávila, 2008, p. 133-150.

HONORATO, T. Indivíduos da ação civilizatória nas escolas normais paulistas (18961913). In: GEBARA, A.; COSTA, C. J.; SARAT, M. (Org.). Leituras de Norbert Elias: processo civilizador, educação e fronteiras. Maringá: EdUEM, 2014, p. 175-190.

HONORATO, T. Instituición escolar y cultura en la civilización moderna. In: KAPLAN, C. V.; ORCE, V. (Orgs.). Poder, prácticas sociales y processo civilizador: los usos de Norbert Elias. Buenos Aires: Noveduc, 2009, p. 109-118.

HONORATO, T. La teoria de Norbert Elias y una agenda de investigación en historia de la educación. In: KAPLAN, C. V.; SARAT, M. (Org.). Educación y procesos de civilización: miradas desde la obra de Norbert Elias. Ciudad Autónoma de Buenos Aires: Editorial de la Faculdad de Filosofia y Letras da Universidad de Buenos Aires, 2016, p. 77-98.

HONORATO, T. Modelos escolares para formação de professores no Estado de São Paulo (1897-1921): o poder à luz de Norbert Elias. Comunicações, UNIMEP. Piracicaba, v. 22, n. $2,123-136,2015$.

HONORATO, T. Reforma Sampaio Dória: professores, poder e figurações. Educação \& Realidade. Porto Alegre, v. 42, n. 4, p. 1.279-1.302, out./dez., 2017.

JULIA, D. A cultura escolar como objeto histórico. Revista Brasileira de História da Educação, v. 1, n. 1, 9-43, 2001.

SÃO PAULO. Decreto n. 397, de 9 de outubro de 1896a. Regulamento da Escola Normal da Capital e Escolas-Modelo anexas. Assembleia Legislativa do Estado de São Paulo, São Paulo.

SÃO PAULO. Decreto n. 400, de 6 de novembro de 1896b. Regimento Interno das Escolas Complementares do Estado. Assembleia Legislativa do Estado de São Paulo, São Paulo.

SÃO PAULO. Decreto n. 2.367, de 14 de abril de 1913. Aprova o regulamento das escolas normais secundárias e anexas. Assembleia Legislativa do Estado de São Paulo, São Paulo.

SÃO PAUlO. Lei n. 1.311, de 2 janeiro de 1912. Aprova o regulamento das Escolas Normais Primárias. Assembleia Legislativa do Estado de São Paulo, São Paulo. 
SOUZA, R. F.; SILVA, V. L. G.; SÁ, E. F. (Org.). Por uma teoria e uma história da escola primária no Brasil: investigações comparadas sobre a escola graduada (1870-1930). Cuiabá: EDUFMT, 2013.

TANURI, L. M. O Ensino Normal no Estado de São Paulo (1890-1930). São Paulo: FEUSP, 1979.

VEIGA, C. G. Obrigatoriedade escolar em Minas Gerais no século XIX: coerção externa e autocoerção. In: VIDAL, D. G.; SÁ, E. F.; SILVA, V. L. G. (Org.). Obrigatoriedade escolar no Brasil. Cuiabá: EdUFMT, 2013, p. 135-152.

VEIGA, C. G. Pensando com Elias as relações entre Sociologia e História da Educação. In: FARIA FILHO, L. M. (Org.). Pensadores sociais e história da educação. Belo Horizonte: Autêntica Editora, 2008, p. 145-172.

VIDAL, D. G.; SÁ, E. F.; SILVA, V. L. G. (Org.). Obrigatoriedade escolar no Brasil. Cuiabá: EdUFMT, 2013.

VIEIRA, C. E. Intelligentsia e intelectuais: sentidos, conceitos e possibilidades para a história intelectual. Revista Brasileira de História da Educação, v. 8, nº 1 [16], 63-85, 2008.

ZABLUDOVSKY, G. Norbert Elias y los problemas actuales de la sociología. México: FCE, 2007.

SITES:

Norbert Elias Foundation. Disponível em: <www.norberteliasfoundation.nl/>. Acesso em 20 de ago. 2017.

Grupo de Pesquisa Processos Civilizadores. Disponível em: <www.uel.br/grupo-estudo/ processoscivilizadores>. Acesso em 20 de ago. 2017.

Grupo de Pesquisa Educação e Processo Civilizador. Disponível em: <http://ufgdgrupoeducacaoeprocessocivilizador.com/>. Acesso em 20 de ago. 2017.

\section{Dados do Autor}

TONY HONORATO

Doutor em Educação pela Universidade Estadual Paulista. Professor Adjunto da Graduação e do Programa de Mestrado em Educação da Universidade Estadual de Londrina. Coordenador do Grupo de Pesquisa Processos Civilizadores. Londrina/PR - Brasil. tonyhonoratu@gmail.com

Submetido em: 04-09-2017

Aceito em:6-11-2017 